\title{
Effective synthesis of n-butyl salicylate over wash coated cordierite honeycomb by zirconia and its mixed oxides: a kinetic study
}

\author{
M. Shyamsundar ${ }^{1,2}$ and S. Z. M. Shamshuddin ${ }^{1 *}$ \\ ${ }^{1}$ Chemistry Research Laboratory, HMS Institute of Technology, NH4, Kyathsandra, Tumkur, Karnataka, India \\ ${ }^{2}$ The Oxford college of Engineering Hosur main road, Bommanahalli, Bangalore, Karnataka, India
}

\begin{abstract}
Cordierite honeycombs were coated with solid acid catalysts such as $\mathrm{ZrO}_{2}(\mathrm{Z}), \mathrm{Mo}(\mathrm{VI}) / \mathrm{ZrO}_{2}(\mathrm{MZ})$ and $\mathrm{Pt}-\mathrm{SO}_{4}{ }^{2}-/ \mathrm{ZrO}_{2}(\mathrm{PSZ})$ were prepared and characterized for their physico-chemical properties. These catalytic materials were characterized for their total surface acidity, crystallinity, functionality, elemental analysis and morphology by using techniques such as $\mathrm{NH}_{3}-\mathrm{TPD}, \mathrm{PXRD}, \mathrm{FTIR}, \mathrm{ICP}-\mathrm{OES}$, SEM and TEM respectively. These honeycomb catalysts were used for the liquid phase transesterification reaction of methyl salicylate (MS) with n-butanol (n-BA). Optimization of reaction conditions such as reaction temperature, reaction time, amount of catalysts and molar ratio of the reactants were carried out to obtain maximum yield of transester (n-butyl salicylate). n-butyl salicylate is obtained as major product and di-butyl ether is obtained as minor product. Highest total transester $70 \%$ obtained by MZ and $80 \%$ n-butyl salicylate and $10 \%$ selectivity of di-butyl ether obtained in the presence of $0.4 \mathrm{~g}$ of honeycomb coated catalysts at a molar ratio of MS: n-BA 2:1, reaction temperature $403 \mathrm{~K}$ and reaction time $4 \mathrm{~h}$. The energy of activation (16.81 and $14.92 \mathrm{~kJ} \mathrm{~mol}^{-1}$ ) and temperature coefficient (1.36 and 1.12) values of the MZ and PSZ were obtained from the kinetic studies. Pre-adsorption studies showed that the transesterification reaction methyl salicylate with n-butyl alcohol over honeycomb catalysts follows Langmuir-Hinshelwood mechanism. A reaction mechanism for transesterification is proposed based on the kinetic data. Reactivation and reusability studies of the honeycomb coated as well as powder form of catalysts up to 6 reaction cycles were also studied.
\end{abstract}

Keywords: Honeycomb; Solid acid catalyst; Transesterification; N-butyl salicylate; Kinetic studies; Monoliths

\section{Introduction}

Cordierite honeycomb (HC) monoliths are the structures which consist of magnesia, silica and alumina in a ratio of 2:5:2 and single blocks of small parallel, non intersecting channels (Theovenin et al., 2003). Honeycomb monoliths as a catalyst support presents excellent operational properties, such as high mechanical strength, high temperature resistance, a low thermal expansion coefficient, low pressure drop and availability in various sizes or shapes. Catalyst coated on HCs have numerous advantages over powder form of catalysts, such as formation of thin layer of catalysts with high active surface area, less amounts of catalysts loaded on the monolith is highly effective, ease of separation and recovery of the catalysts from a liquid reaction mass (Mohamed et al., 2012; Sharma et al., 2009).

Honeycomb coated catalysts are widely used in industrial applications which involve gas phase reactions like combustion of VOCs, automotive applications, ozone abatement in aircrafts and selective reduction of NOx (Heck et al., 2001; Liu Bo et al., 2015). However, HCs coated with solid acid catalysts have not been much examined so far in the field of organic synthesis involving liquid or vapour phase reactions (Thimmaraju et al., 2012; Lachman et al., 1986; Okada et al., Klinghoffer et al., 1998; Lachmann et al., 1992; Trimm, 1995; Knickerbockers et al., 1993;
Subramanian et al., 1993). Similar procedures have been perform coating the monolith walls with support materials called wash coat-like $\mathrm{\gamma}-\mathrm{Al}_{2} \mathrm{O}_{3}, \mathrm{TiO}_{2}, \mathrm{ZrO}_{2}$ etc, to obtain a high surface area and abundant pores since cordierite itself exhibits negligible porosity and offers little contribution to catalytic action (Arai et al., 2009). About the deposition method for active phases, different strategies, such as hydrothermal synthesis sol-gel process, chemical vapor deposition and dip-coating, have been employed for initially coating the monolith channels with an additional support material, which is then followed by the accretion of active phases to the coating of ready-made catalyst (Thimmaraju et al., 2012; Nijhuis et al., 2001).

It is worthwhile to find out suitable environmentally benign solid catalysts for the transesterification reaction considering the fact that the existing procedures require expensive or corrosive acids, bases and solvents which cannot be reuse and recycle because of tedious procedures (Otera et al., 1993; Corma et al., 1998; Illankumaran et al., 1999; Otera et al., 1991; Staton et al., 1998; D' Souza et al., 2004; Banzquart et al., 2001; Kim and Lee, 1999). Transesterification is an industrially important acid catalyzed reaction with wide range of applications. 
Consequently, a number of protocols for transesterification are time consuming and the catalysts used are toxic and corrosive in nature have been extensively studied and reported which are catalyzed by conventional organic acids, bases and enzymes. Though, it has known that the reaction seems accelerated by either homogeneous or heterogeneous conditions. Keeping in view of environmental concern still noteworthy to propose a catalyst which is ease of separation from the reaction mixture and more reactivable and reusability (Furlan et al., 1998; Martin Alonso et al, 2009; Qureshi et al., 2009; Ghesti et al., 2009; Monica et al., 2009; Yong and Eun, 2009; Yip et al., 2007; Saravanamurugan et al., 2008; Srinivas et al., 2004).

The salicylates are important group of esters used for the synthesis of drugs, preservatives, plasticizers pharmaceuticals, sun tan preparations, perfumes, sweeteners and solvents (Vane et al., 1992). Predominantly, n-butyl salicylates is a colourless transparent liquid used in many fragrance compounds, and find applications as decorative cosmetics, fine fragrance ingredients and other toiletries like non-cosmetic products such as detergents and household cleaners (Lapczynski et al., 2007).

In continuation of our research work (Shyamsundar et al., 2013; Shyamsundar et al., 2015) on the application of cordierite honeycomb monoliths coated with zirconia and its modified forms, in the present article synthesis, characterization and catalytic activity of cordierite honeycomb coated with solid acids catalysts such as $\mathrm{ZrO}_{2}, \mathrm{Mo}(\mathrm{VI}) / \mathrm{ZrO}_{2}$ and $\mathrm{Pt}-\mathrm{SO}_{4}{ }^{2-} / \mathrm{ZrO}_{2}$ is described.

The main goal of this article were to synthesize n-butyl salicylate over honeycomb coated solid acid catalysts such as zirconia and its customized forms (MZ, PSZ) in acid catalyzed transesterification of methyl salicylate (MS) and n-butyl alcohol (n-BA). The catalytic materials used for the present study were characterized total surface acidity, crystallinity, functionality, elemental analysis and morphology by using suitable techniques. The total transester yield and percentage selectivity towards the required product were optimized by varying parameters such as reaction temperature, reaction time, amount of catalysts and molar ratio of reactants. The obtained reaction products were characterized by gas chromatography with the flame ionization detector. In order to find out the right catalysts for the transesterification of MS and n-BA based on the kinetics reaction was carried out to obtain the data such as temperature coefficient and energy of activation (Ea). A reactant pre-adsorption experiment was also conducted and a trial was made to fit the data in Langmuir-Hinshelwood mechanism. Regeneration and reutilization of HC coated catalysts up to 6 reaction cycles were studied.

\section{Materials and methods}

Methyl salicylate, n-butanol and n-butyl salicylate were purchased from the Loba Chemie Pvt Ltd. While honeycomb monoliths (silica: alumina: magnesia) from Shreya ceramics
Baroda. The purchasd chemicals were confirmed by gas chromatography. Catalytic materials such as Zirconyl nitrate, ammonium molybdate, chloroplatinic acid, LR grade were purchased from Lab supplies India Pvt Ltd.

Preparation of catalytic materials on the cordierite honeycomb monolith

In the current work the active catalyst such as $\mathrm{ZrO}_{2}$, Mo (VI) $/ \mathrm{ZrO}_{2}$ and $\mathrm{Pt}-\mathrm{SO}_{4}{ }^{2-} / \mathrm{ZrO}_{2}$ were coated on the $\mathrm{HC}$ which was already wash coated with zirconia. Sometimes direct coating of an active catalyst on a non-wash coated bare honeycomb may lead to the loss of active catalyst during its application in an organic reaction due to poor adherence of the active catalyst. Wash coated monoliths lies on the inner surface of the channels and increases the internal surface area Coating of a catalytic layer on the surface of the $\mathrm{HC}$ by $\mathrm{ZrO}_{2}(\mathrm{Z})$ In this method calculated amount of zirconyl nitrate $(5 \mathrm{~g})$ and required amount of de-ionized water stirred for some time to obtain a clear solution. The resulting solution was coated on a $\mathrm{HC}$ by dipping and drying in a furnace at $673 \mathrm{~K}$ with desired amount of coating.

Coating of a catalytic layer on the surface of HC by Mo (VI) $/ \mathrm{ZrO}_{2}(\mathrm{MZ})$

A known amount of zirconyl nitrate (3 g) and ammonium molybdate $(0.4 \mathrm{~g})$ with required amount of de-ionized water in a china dish was made into slurry. The resulting slurry was coated on a wash coated HC following by dipping and drying steps in a furnace preheated at $673 \mathrm{~K}$. Process was repeated until we get $\sim 0.4 \mathrm{~g}$ of $\mathrm{MZ}$ was coated on the $\mathrm{HC}$.

Coating of a catalytic layer on the surface of $\mathrm{HC}$ by $\mathrm{Pt}_{-} \mathrm{SO}_{4}{ }^{2-} / \mathrm{ZrO}_{2}$ (PSZ)

A known amount of zirconyl hydroxide $(4 \mathrm{~g}), 6 \mathrm{M}$ sulphuric acid $(2 \mathrm{ml})$ solution and little amount of de-ionized water was made into a paste. The paste was made into dried at $393 \mathrm{~K}$ for $12 \mathrm{~h}$. The dried materials was dried and powdered well this was taken in a china dish, $1 \%$ of $\mathrm{H}_{2} \mathrm{PtCl}_{6}(2 \mathrm{ml})$ was added with required amount of de-ionized water added to make a slurry. Finally the resulting slurry was coated on a HC by dipping and drying in a furnace at $673 \mathrm{~K}$. Process is repeated until we get $0.4 \mathrm{~g}$ of PSZ was coated on HC (Patil et al., 2008).

Finally, all the $\mathrm{HC}$ coated catalytic materials were calcined at $873 \mathrm{~K}$ for $4 \mathrm{~h}$.

Weights of the honeycomb before and after coating the catalysts were measured. The difference between the two weights gives the amount of catalysts got coated onto the honeycomb.
i.e., if $\mathrm{X} 1=$ weight of honeycomb before coating the catalysts.
$\mathrm{X} 2$ = weight of the honeycomb after coating the catalysts.

Then, $(\mathrm{X} 2-\mathrm{X} 1)$ is the amount of the catalyst coated on to the honeycomb. 


\section{Preparation of catalytic materials in their powder catalysts}

Pure zirconia is prepared by a required amount of zirconyl nitrate and de-ionized water to make a paste and dry at hot air oven at $673 \mathrm{~K}$ for $12 \mathrm{~h}$. $\mathrm{Mo} / \mathrm{ZrO}_{2}$ is prepared by calculated amount of ammonium molybdate and zirconyl nitrate with $10 \mathrm{ml}$ of de-ionized water to make paste and dry at $673 \mathrm{~K}$ for $12 \mathrm{~h}$.

A known amount of zirconyl hydroxide ( $2 \mathrm{~g}), 6 \mathrm{M}$ sulphuric acid $(1 \mathrm{ml})$ and de-ionized water $(5 \mathrm{ml})$ to make paste in a ceramic dish and dry at hot air oven at $393 \mathrm{~K}$ for $12 \mathrm{~h}$. Then the powder form with the solution of Hexachloro platinic acid $(1 \mathrm{ml})$ were taken in a china dish make a paste by using small amount of de-ionized water. The resulting paste was then dried in a hot air oven at $393 \mathrm{~K}$ for $12 \mathrm{~h}$. Therefore, all the catalytic materials calcined at $823 \mathrm{~K}$ for $4 \mathrm{~h}$ in a muffle furnace. These powder forms of catalytic materials used for the comparative studies over honeycomb coated catalytic materials.

\section{Catalytic activity studies}

The catalytic activity of the honeycomb coated with Z, MZ and PSZ was examined in transesterification of methyl salicylate (MS) with n-butyl alcohol (n-BA).

In general, a liquid phase transesterification reaction was carried out by taking methyl salicylate ( $2 \mathrm{mmol})$ and n-butyl alcohol (1 mmol) along with catalytic material (either HC coated or powder forms of $\mathrm{Z}, \mathrm{MZ}$ and PSZ) were placed in a specially made reactor and refluxed for a stipulated period of time (39). After a specific period of time the reaction mass was cooled to room temperature, the honeycomb coated catalyst was separated from the reaction mass and the products obtained by the transesterification shown in Scheme 1. The filtrate was examined quantitatively by GC (Mayura) fixed with $10 \%$ carbowax column which is connected to a flame ionization detector (FID) as well as qualitatively by GCMS (Varian). Typical GC operating conditions (Thimmaraju et al.,) were, FID Temperature $=250^{\circ} \mathrm{C}$, Split flow $=100 \mathrm{~mL} / \mathrm{min}$, Carrier gas $=$ Nitrogen at $1 \mathrm{~mL} / \mathrm{min}$, Temperature programming: 150 to $250{ }^{\circ} \mathrm{C}$ (at $\left.10^{\circ} \mathrm{C} / \mathrm{min}\right)$.

To optimize the reaction condition parameters such as temperature, time, molar ratio of the reactants and amount of the catalysts were varied. Kinetics studies were conducted in the reaction time from the 0 to $10 \mathrm{~h}$, temperature varies from 383 to $423 \mathrm{~K}$, amount of catalysts in the range of 0.1 to $0.4 \mathrm{~g}$ and reactants was varied in the range of 1:1 to $4: 1$. Finally, the effect of nature of catalysts and kinetic studies to find out a facile catalyst for the transesterification reaction.

\section{Regeneration of HC coated catalytic materials}

To study the reutilization and regeneration of the HC coated catalytic materials was recovered easily from the liquid reaction mixture, washed with acetone and dried at $393 \mathrm{~K}$ for $2 \mathrm{~h}$ and followed by $873 \mathrm{k}$ for $1 \mathrm{~h}$ to remove organic

\section{Scheme1}

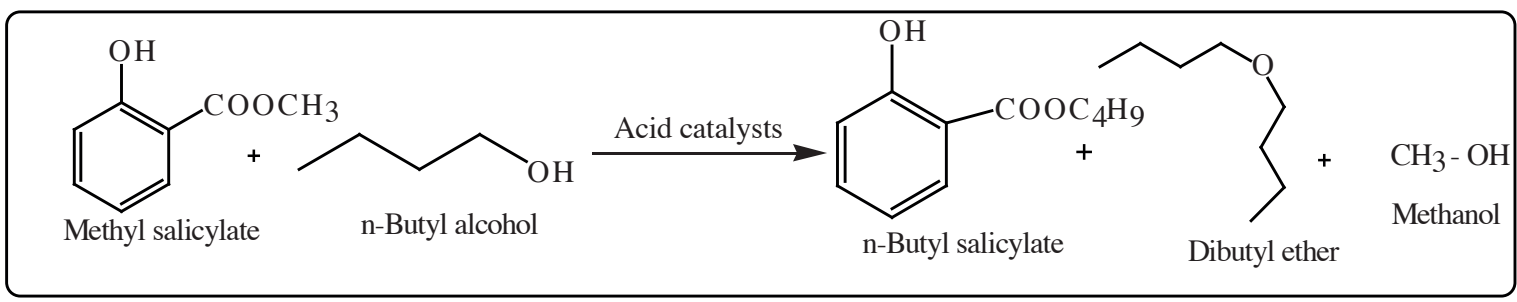

Scheme 2. Possible reaction mechanism of n-butyl salicylate formation over honeycomb coated solid acid catalysts

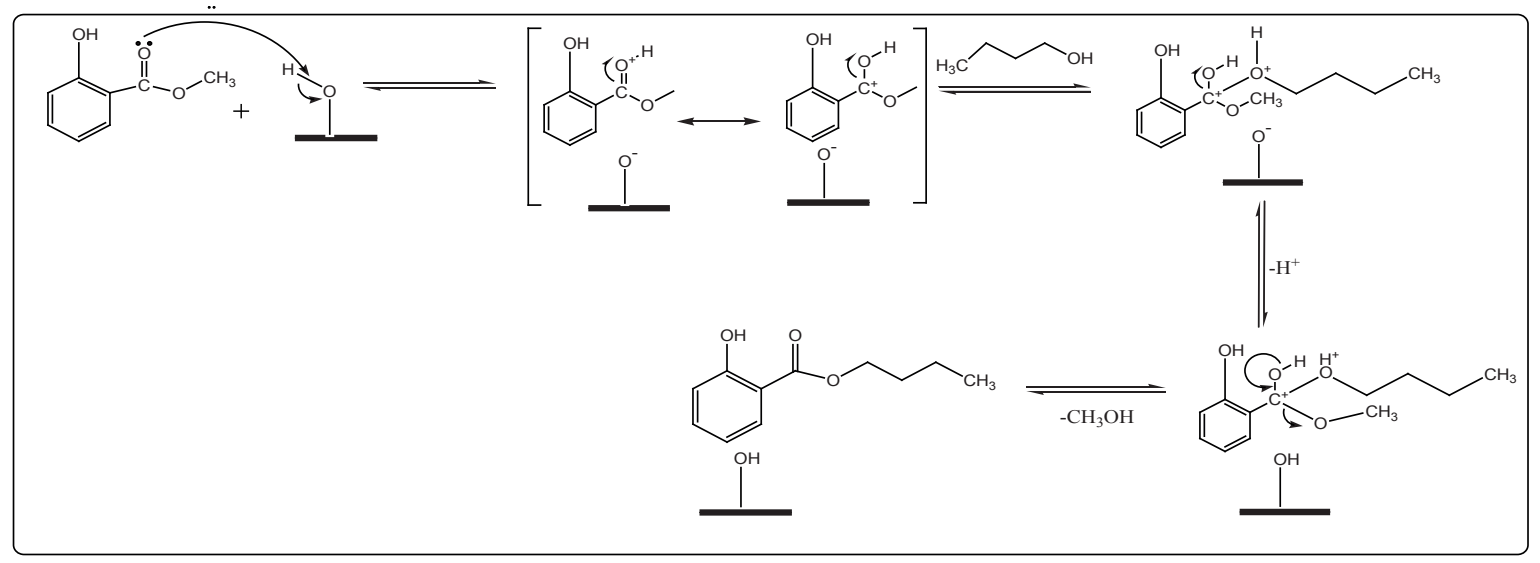


impurities. Consequently, regenerated HC monolithic catalysts used for the n-butyl salicylate synthesis under similar conditions with fresh reaction mixture for 5 successive reaction cycles.

\section{Results and discussion}

Physico-chemical techniques of honeycomb coated catalytic materials

The characterization of the materials (both powder and HC coated form). The total surface acidity (TSA) value was analyzed by temperature program desorption of ammonia $\left(\mathrm{NH}_{3}\right.$-TPD) experiments were studied on a pulse chemisorb instrument (Micromeritrics) and also by n- butyl amine back titration method with anhydrous benzene solvent. The amount of Mo, S and Pt were estimated by Inductively Coupled Plasma-Optical Emission Spectrometer (ICP-OES) analysis techniques using Thermo-icap 5500 series instrument. NOVA 1000 Quanta chrome high- speed gas sorption analyzer instrument was used to measure the specific surface area of all the prepared catalytic materials. Powder X-Ray Diffraction (PXRD) patterns were recorded an X-ray Philips diffractometer equipped with a nickel filtered $\mathrm{Cu} \mathrm{K} \alpha(\lambda=1.5418 \mathrm{~A} 0)$ using a graphite monochromatic with a scanning range of 2 theta $=0-700$. The FTIR spectrum was recorded with $4 \mathrm{~cm}-1$ resolution using a Nicolet IR-200 FT-IR spectrometer in the range of 400-4000 cm-1 using KBR crystal as a standard reference. SEM images were obtained, using a JEOL microscope model JEM 6300 (Japan). Transmission electron microscopy (TEM) images were recorded on a JEOL 2010 with an acceleration voltage of $200 \mathrm{kV}$ IISC Bangalore.

\section{Total surface acidity (TSA) studies and ICP-OES studies}

The acid site distribution of $\mathrm{HC}$ coated zirconia and its customized forms by $\mathrm{NH}_{3}$-TPD and also values obtained by n-butyl amine back titration methods are given in Table I. TSA values of the solid acids were used for the present work followed the order: $\mathrm{Z}<\mathrm{MZ}<\mathrm{PSZ}$.

The catalytic materials used for the present study are Z, MZ and PSZ and these materials are prepared by slurry coating

Table I. Characterization of catalytic materials used for the present study

\begin{tabular}{cccc}
\hline & $\begin{array}{l}\text { Solid acid } \\
\text { distribution }\end{array}$ & \multicolumn{2}{c}{$\begin{array}{c}\text { Metal ions by ICP - } \\
\text { OES method }\end{array}$} \\
\hline $\begin{array}{c}\text { Solid acid } \\
\text { catalysts }\end{array}$ & $\begin{array}{c}\text { BET surface } \\
\text { area }\end{array}$ & TSA & \\
\hline $\mathrm{ZrO}_{2}$ & $43(49)$ & $0.43(0.44)$ & $5.65 \%(\mathrm{Mo})$ \\
\hline $\mathrm{MZ}$ & $96(114)$ & $1.25(1.28)$ & $\begin{array}{c}2.6 \%(\mathrm{~S}) \text { and } \\
1.5 \%(\mathrm{Pt})\end{array}$ \\
\hline $\mathrm{PSZ}$ & $121(143)$ & $1.49(1.52)$ & \\
\hline
\end{tabular}

method. In the present case pure zirconia seems to be lowest acidic and it shows only 'weak' and 'moderate' acidic sites. But, MZ shows the existence of 'moderate' and 'strong' acidic sites attributed sue to the formation of electron deficient states. PSZ shows the existence of 'strong' and 'very strong' acidic sites. On the other hand, the TSA values of honeycomb coated material as well as powder form were found to be independent. There was no difference between the TSA values of honeycomb coated form as well as powder forms (Shyamsundar et al., 2015; Shyamsundar et al., 2013). The actual percentage of the metal ions obtained for the present study estimated by ICP-OES techniques are given in the Table I, Column 4.

\section{BET Surface area}

The surface area of the HC coated catalysts such as Z, MZ and PSZ catalysts were given in the Table 1 . The surface area of the catalysts depends on the concentration of Mo and $\mathrm{Pt}_{-} \mathrm{SO}_{4}{ }^{2-}$ ions over zirconia. While the percentage of solid acid catalyst loading on the surface of the bare honeycomb. Zirconia is found to be least among the catalytic materials compared to MZ has been increased two fold surface area compared to zirconia and PSZ catalysts. This shows stabilization effect of zirconia.

\section{PXRD studies}

XRD patterns of zirconia and its modified forms such as MZ and PSZ were recorded in the range of $2 \theta=0-700$. The sharp diffraction lines at $2 \theta=28.3,24.46$ and 31.58 degrees

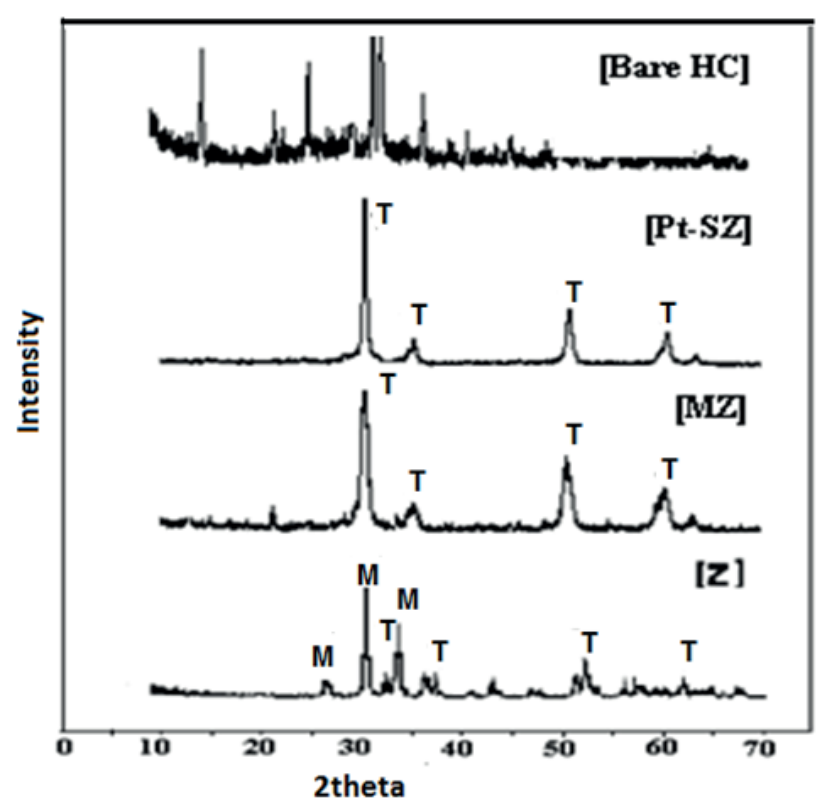

Fig. 1. PXRD patterns of $\mathrm{HC}$ coated $\mathrm{Z}, \mathrm{MZ}, \mathrm{Pt}-\mathrm{SZ}$ and Bare HC [M- monoclinic $\mathrm{ZrO}_{2}$, Tetragonal 


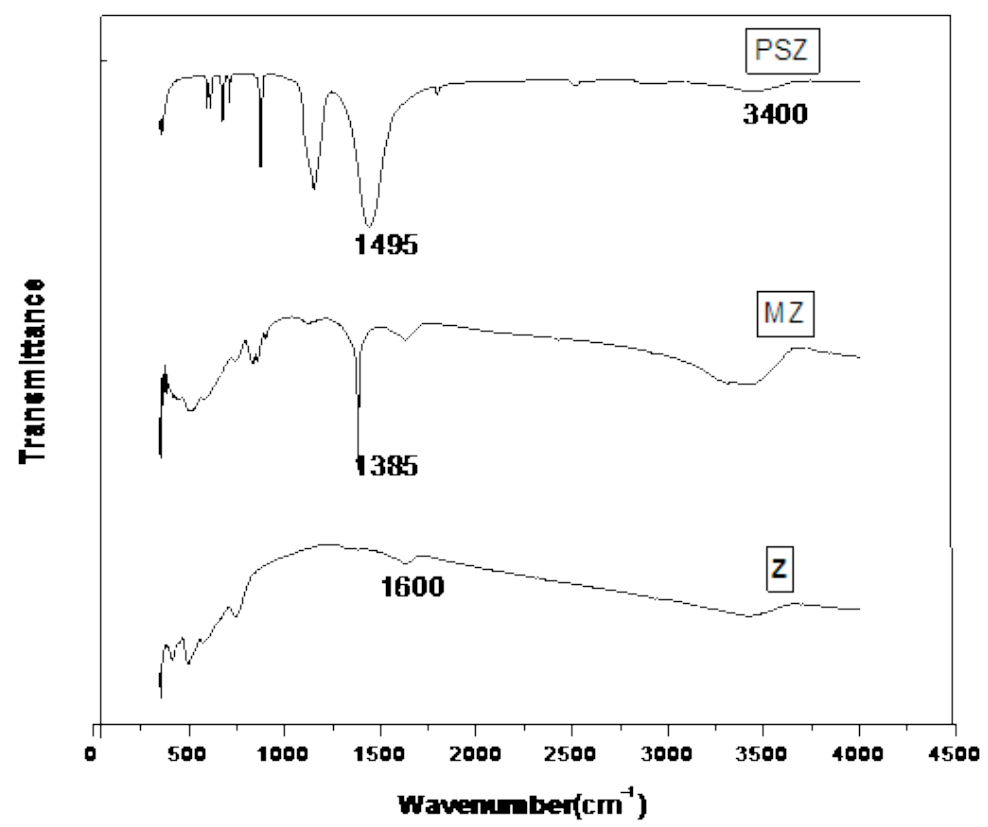

Fig. 2. FTIR spectra of $\mathrm{HC}$ coated Z, MZ and PSZ

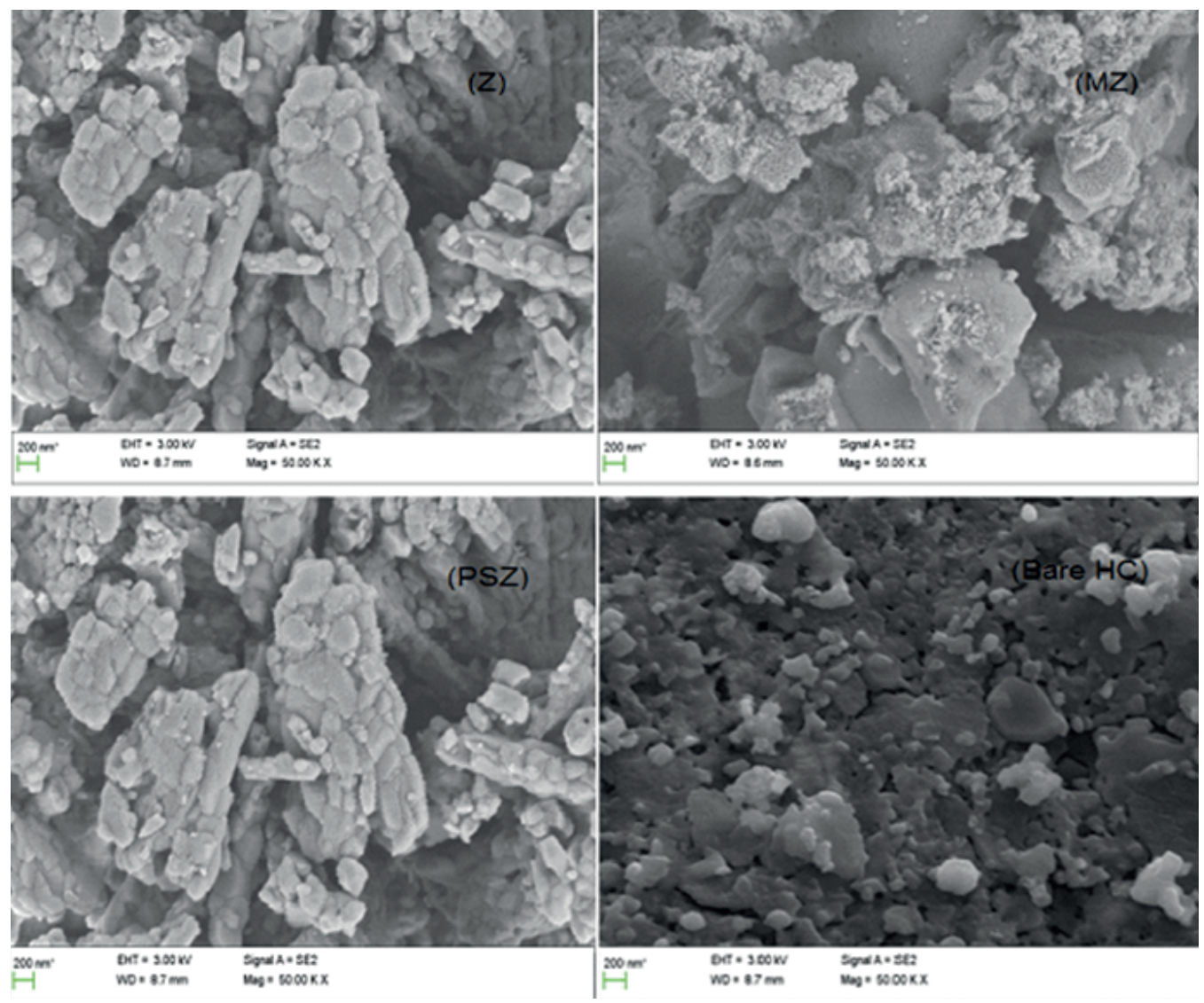

Fig. 3. SEM images of HCs coated with Z, MZ, PSZ and Bare HC 

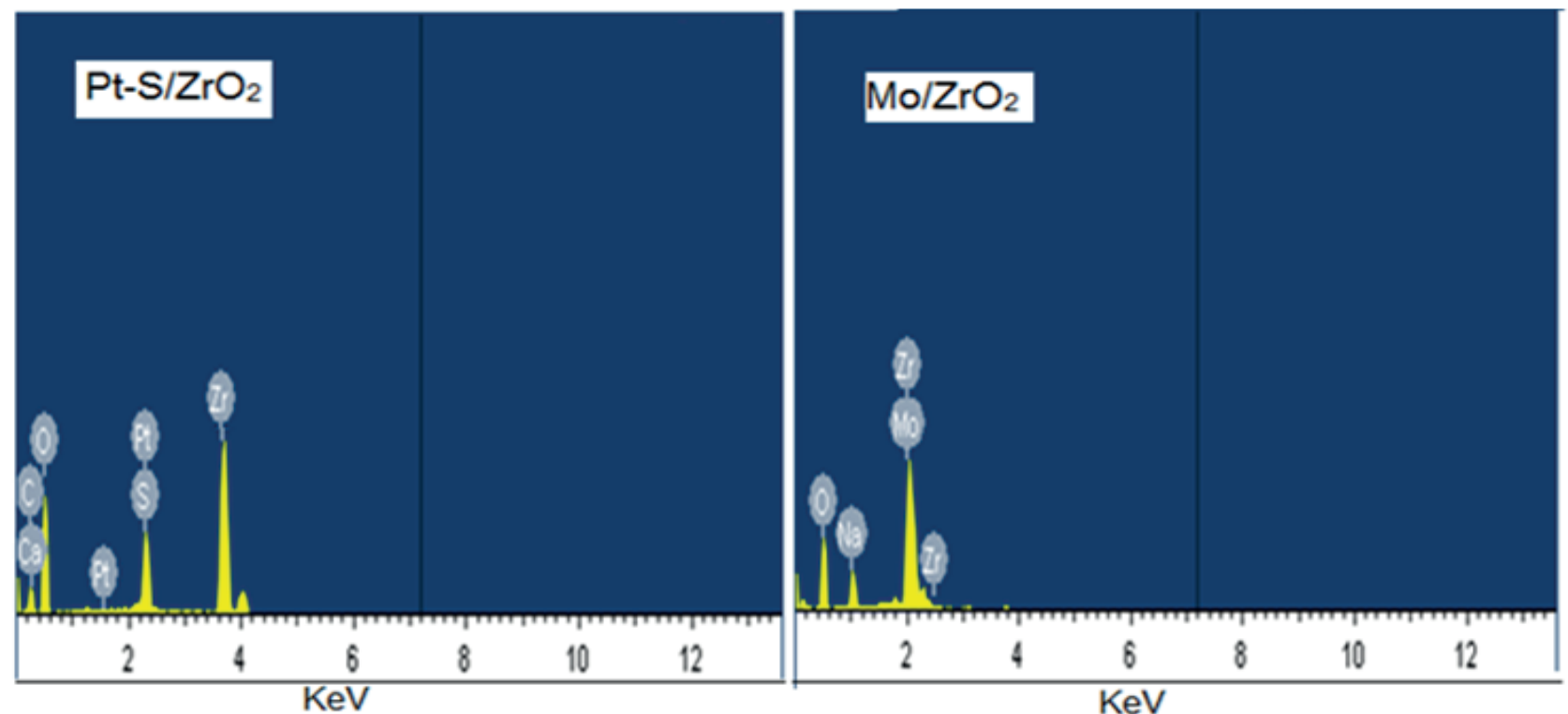

Fig. 4. EDX Spectrum of MZ and PSZ
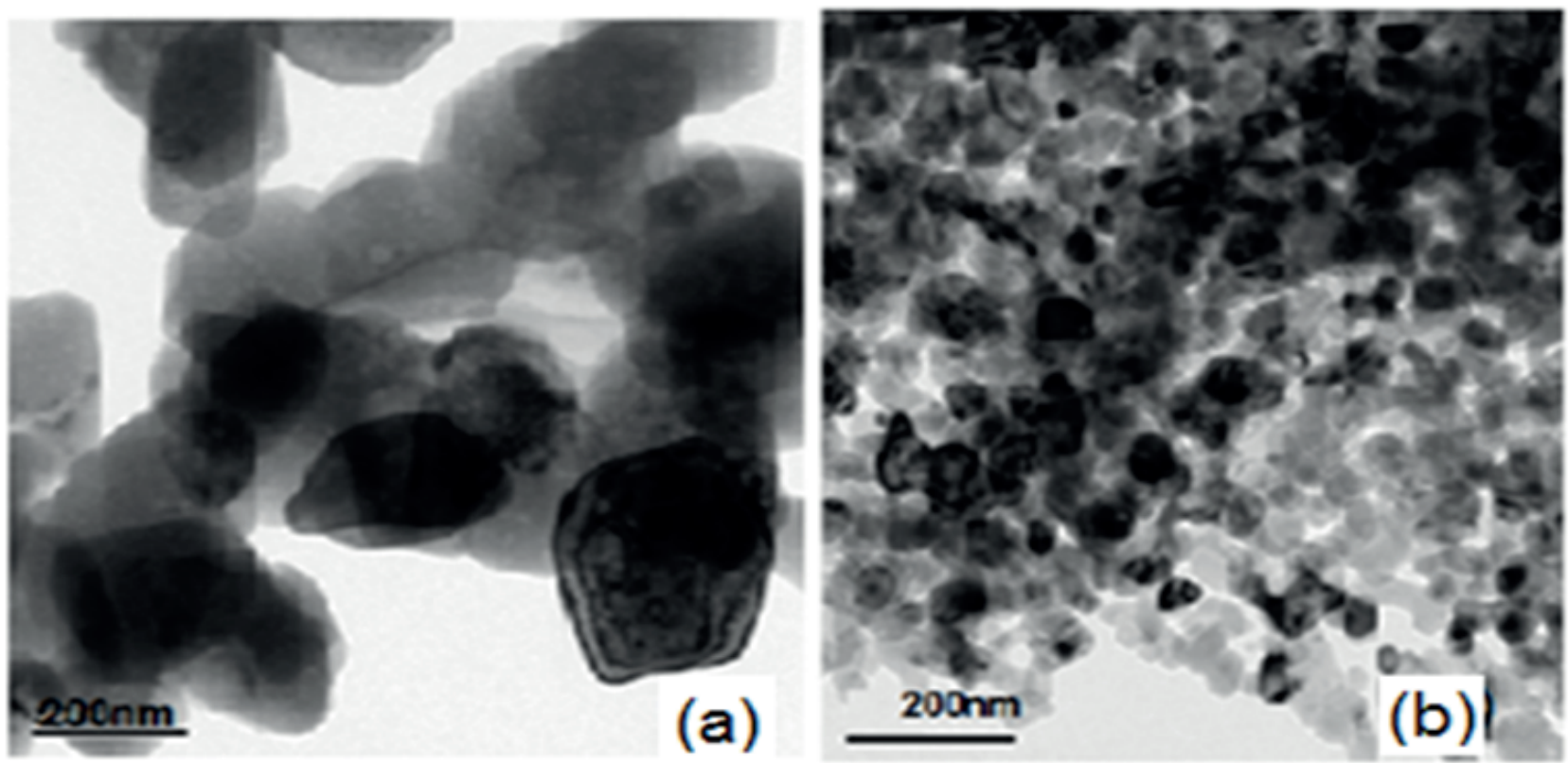

Fig. 5. TEM images of HC coated (a) MZ (b) PSZ catalysts

correspond to the monoclinic form and the lines at $2 \theta=$ $30.27,35.3$ and 49.82 degrees are due to tetragonal form of $\mathrm{ZrO}_{2}$. The tetragonal phase was found to dominate over the monoclinic phase when dopants such as (Mo (VI) or $\left.\mathrm{Pt}_{-} \mathrm{SO}_{4}{ }^{2}-\right)$ were incorporated into the hydrous zirconia structure. The suppression of monoclinic phase was hardly observed in the MZ and PSZ has been reported in the literature (Reddy et. al., 2009; Reddy et al., 2008). In case of PXRD pattern of bare honeycomb was effectively covered with active materials and there was no peaks related to bare honeycomb (Thimmaraju et al., 2012). The average crystalline size of the catalytic materials was used for the 
preset study is found to be $100-150 \mathrm{~nm}$ from Scherer equation.

\section{$\mathrm{D}=\mathrm{K} \lambda / \beta \operatorname{Cos} \theta$}

\section{FTIR Studies}

The FTIR spectra of $\mathrm{ZrO}_{2}$ and its modified forms are shown in Fig. 2 respectively. A comparison of the spectra of pure zirconia and its customized forms confirms the existence of molybdate and Pt-sulphate species, broad bands in the region of $3350-3450 \mathrm{~cm}^{-1}$ indicated by the existence of surface hydroxyl groups (Vijaykumar et al., 2013). The PSZ showed a peak at 1495 and $1150 \mathrm{~cm}^{-1}$ indicating the existence of both Bronsted and Lewis acidity respectively.

In case of Mo (VI)/ZrO 2 dominant band at $975 \mathrm{~cm}^{-1}$ and the weak signal that appears at $1089 \mathrm{~cm}^{-1}$ are feature of the stretching vibration mode (frequency) of $\mathrm{Mo}=\mathrm{O}$ terminal bonds and the band at $836 \mathrm{~cm}^{-1}$ is linked with the vibration of Mo-O-Mo bridging bonds (Davydov et al., 2003).

\section{SEM and TEM Images}

The SEM images clearly show a very wide distribution in texture and particle size. Both the morphologies show the active components equally spread on the surface of the honeycombs and are almost uniformly distributed with the particle size. Modified $\mathrm{ZrO}_{2}$ shows flake like appearances with existence of certain cracks on the surface which may be due to the loss of water molecules during calcinations (Reddy et al., 2007). The EDX spectrum of the catalytic materials such as MZ and PSZ shows the composition of the zirconia, molybdenum, platinum and sulphur. These materials show the presence of atomic weights similar to the catalytic composition.

TEM images clearly show zirconia has spherical shape of crystalline sizes were also in good compliance with crystalline sizes acquired from the PXRD. The average particle size of MZ and PSZ was found to be 180-200 nm. These morphological changes observed higher surface area due to incorporation of $\mathrm{Mo}(\mathrm{VI})$ and $\mathrm{Pt}-\mathrm{SO}_{4}{ }^{2-}$ species.

\section{Catalytic activity studies (Transesterification)}

In order to influence the liquid phase transesterification reaction, the reaction was carried between the methyl salicylate (MS) and n-butyl alcohol (n-BA) in presence of $\mathrm{HC}$ coated solid acids Z, MZ and PSZ catalysts (Scheme 1). When the reaction was carried out with the bare honeycomb it shows very less conversion of products. Therefore transesterification is a $\mathrm{HC}$ coated catalyzed reaction. Hence all the HC coated catalysts as well as powder form of catalysts showed very active in this reaction (Thimmaraju et al., 2015).

Effect of nature of catalysts (HC coated as well as powder forms)

The catalytic activity of honeycomb coated with $\mathrm{Z}$ or $\mathrm{MZ}$ or PSZ was compared with their powder form. The results indicate that $\sim 1.8$ fold increases in the catalysts activity of HC catalysts was observed (Table II). For instance PSZ (powder form) showed $38 \%$ yield of trans-ester whereas PSZ (HC coated form) showed $80 \%$ yield of transester. Higher activity of HCs catalysts could be attributed to the dispersion of the catalysts in the form of thin layer on the surface of channels present in the $\mathrm{HC}$ which is not possible when the catalysts is used in the powder form. The minimal catalyst loading in case of HC catalysts is compensated by the higher competence due to the high quality transfer characteristics. This may be indicated to the availability of more number of shifting centres on the surface of the HC catalysts due to homogeneous dispersion of the catalysts (Thimmaraju et al., 2012; Nijhuis et al., 2001). Unfortunately, no change in the selectivity of either n-butyl salicylate (n-BS) or di-butyl ether (DBE) was observed over both HC coated form as well as powder form of a catalyst.

\section{Effect of reaction temperature}

The influence of reaction temperature on the transesterification of MS and n-BA is investigated by varying the temperature range of 383 to $423 \mathrm{~K}$ over $\mathrm{HC}$ coated Z, MZ and PSZ. The n- BA conversion has been increased with the increase the temperature of the reaction accompanied by an

Table II. Catalytic materials used for the transesterification of MS with n-BA over solid acids in both powder and honeycomb coated forms

\begin{tabular}{lccc}
\hline Catalyst & Total transester & Selectivity of & Selectivity of \\
\hline & Yield & n - BS & DBE \\
\hline Z (HC) & 32 & 100 & - \\
\hline Z (powder) & 18 & 100 & - \\
\hline MZ (HC) & 70 & 100 & - \\
\hline MZ (powder) & 32 & 100 & - \\
\hline PSZ (HC) & 80 & 90 & 10 \\
\hline PSZ (powder) & 38 & 88 & 12 \\
\hline
\end{tabular}

$\overline{\text { Reaction conditions for Column 3: Reaction time } 4 \mathrm{~h} \text {; reaction temperature }}$ $403 \mathrm{~K}$; weight of $\mathrm{HC}$ coated catalyst $0.4 \mathrm{~g}$; molar ratio of MS: n-BA 2:1]

increase in the selectivity of n-butyl salicylate over the $\mathrm{HC}$ coated $\mathrm{Z}$ and $\mathrm{MZ}$ catalysts. However, the tendency of self condensation of n-butyl alcohol increases with the increase in temperature resulting in the formation of di-butyl ether (DBE). Hence, $403 \mathrm{~K}$ could be set as an optimized temperature for the present transesterification reaction to get highest possible yield (\%). The obtained results are shown in the Fig. 6. 


\section{Effect of amount of catalysts}

The HCs with different amounts of MZ or PSZ catalysts in the range of 0.1 to $0.4 \mathrm{~g}$ were coated. The effects of quantity of the active catalyst coated on $\mathrm{HC}$ were studied in transesterification reaction of $\mathrm{MS}$ with $\mathrm{n}-\mathrm{BA}$, and the results are obtainable in Fig. 7. It can be seen that as the amount of catalyst coated on $\mathrm{HC}$ increased from 0.1 to $0.3 \mathrm{~g}$, the
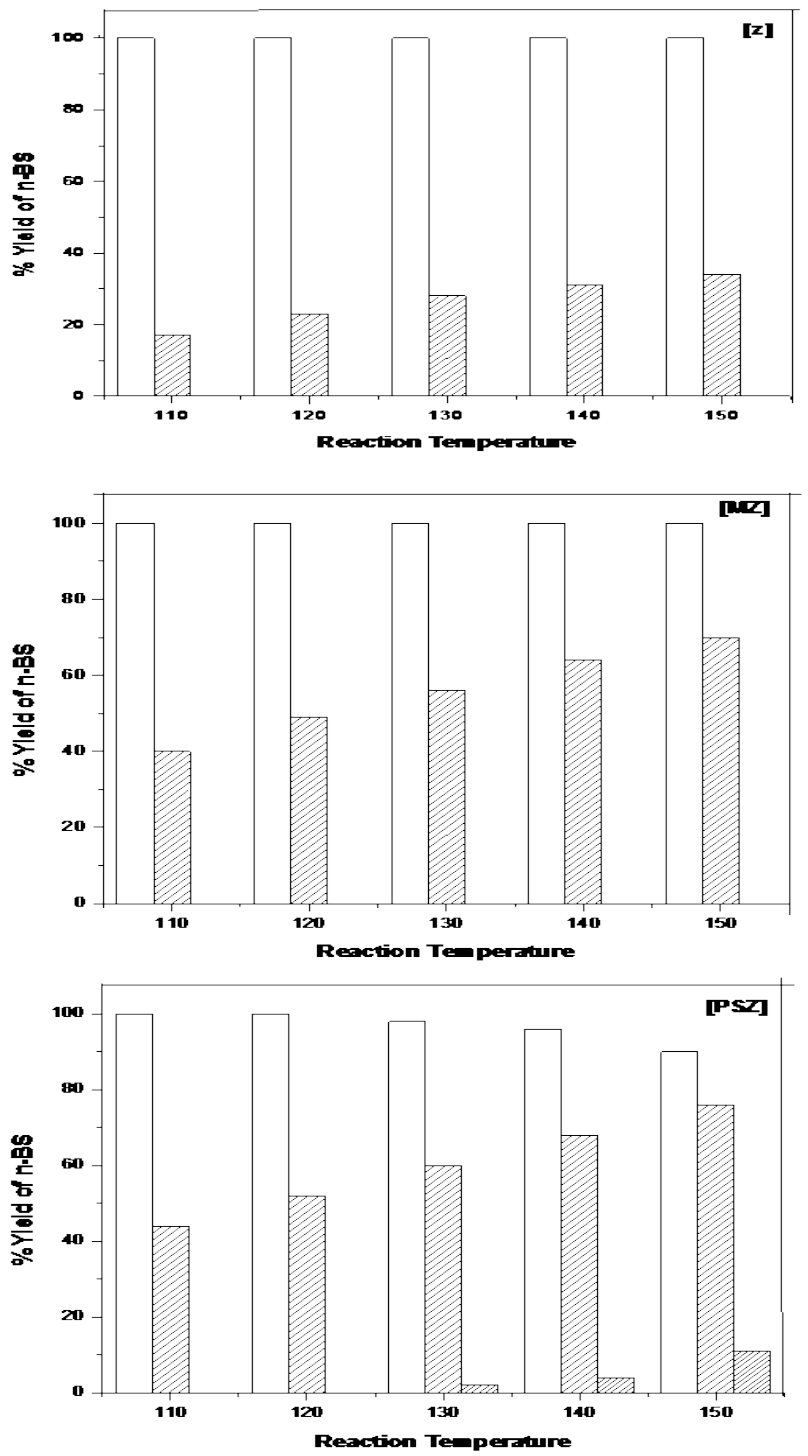

Fig. 6. Influence of reaction temperature [Reaction conditions: reaction temperature $=403 \mathrm{~K}$, weight of the catalysts $\mathrm{HC}$ coated $0.4 \mathrm{~g}$, Molar ratio 2:1, reaction time $=4 \mathrm{~h}$, Selectivity of $n-B S$, Conversion of n-BA and Selectivity of n-DBE]

conversion of n-BA also increased. But an increase in the amount of catalysts beyond $0.3 \mathrm{~g}$ did not result in a reasonable increase in the conversion of n-BA to n-BS. This shows that the coating of a catalyst up to $0.3 \mathrm{~g}$ is suitable to get good conversion of $\mathrm{n}-\mathrm{BA}$.

\section{Effect of reaction time}

The effect of reaction time on the conversion of $\mathrm{n}-\mathrm{BA}$ and selectivity towards the n-BS over $\mathrm{HC}$ coated with $\mathrm{MZ}$ and PSZ was also taken up by changing the reaction time from 0 to $10 \mathrm{~h}$ and the results are presented in the form of a graph as shown in Fig. 8. The conversion of n-BA increased rapidly in the beginning (up to $2 \mathrm{~h}$ ) and gradually levelled off after $6 \mathrm{~h}$. On the other hand, the conversion of n- BA increased from 10 to $40 \%$ in the first $4 \mathrm{~h}$ and only $42 \%$ in the next $4 \mathrm{~h}$ over MZ.
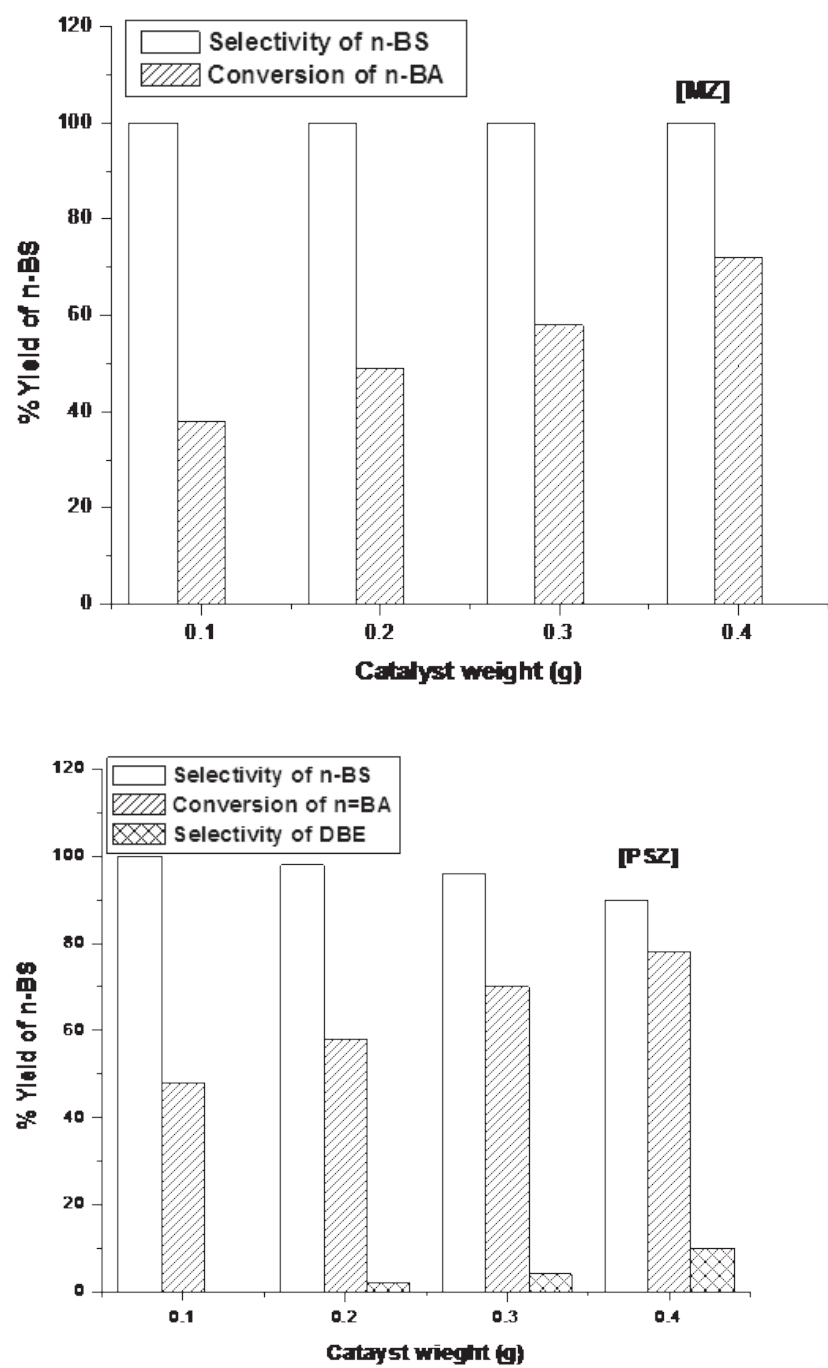

Fig. 7. Influence of amount of catalysts [Reaction conditions: reaction temperature $=403 \mathrm{~K}$, weight of catalyst $=0.4 \mathrm{~g}$ HC coated, Molar ratios $=\mathrm{MS}$ : n-BA (2:1), reaction time $4 \mathrm{~h}$ ] 
Although, in case of PSZ (honeycomb coated), the conversion of n-BA has increased from $25 \%$ in the first $2 \mathrm{~h}$ and in next $4 \mathrm{~h} 65 \%$ has been improved. The amount of n-BA to $\mathrm{n}-\mathrm{BS}$ increased up to $88 \%$ in the next $10 \mathrm{~h}$.
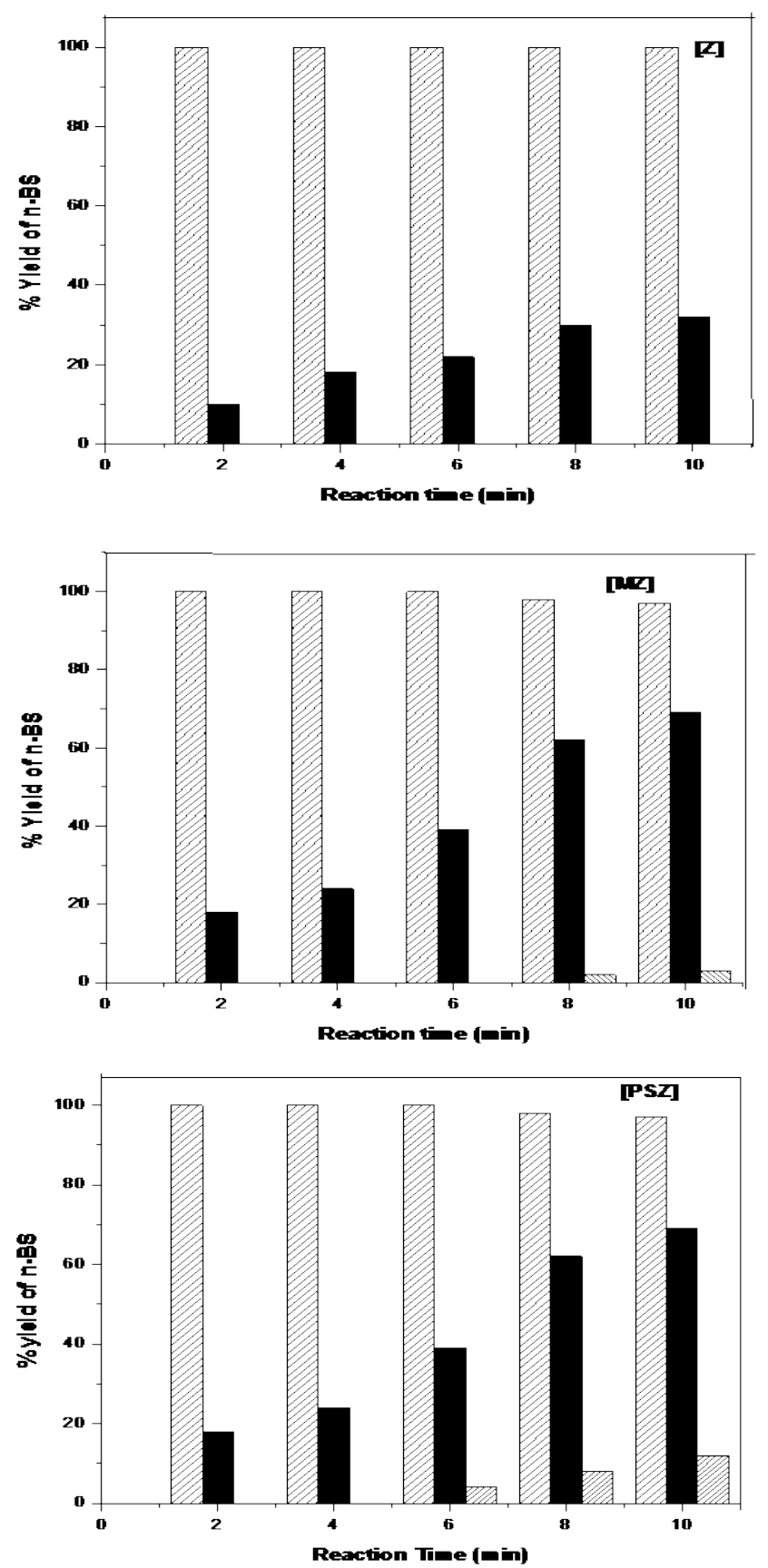

Fig. 8. Influence of reaction time [Reaction conditions: reaction temperature $=403 \mathrm{~K}$, weight of $\mathrm{HC}$ coated catalyst $0.4 \mathrm{~g}$, molar ratios $2: 1$, reaction time $=4 \mathrm{~h}$, Selectivity of n-BS, Conversion of n-BA and Selectivity of DBE]
Selectivity of n- butyl salicylate remained $100 \%$ up to $6 \mathrm{~h}$ over $\mathrm{HC}$ coated with MZ, but after $6 \mathrm{~h}$ a thick oily compound started forming on the surface of the HC which couldn't be separated or detected by GC or GC-MS. Therefore a reaction period of $4 \mathrm{~h}$ seems to be needed for reasonable conversion of n-butyl alcohol to n-butyl salicylate.

\section{Effect of molar ratio of the reactants (MS: $n-B A)$}

In order to study the effect of mole ratio of methyl salicylate and n-butyl alcohol reaction were carried out to different molar ratios such as 1:1, 1:2, 1:3, 1:4, 2:1, 3:1, 4:1 over MZ and PSZ HC coated catalysts. The yield of n-BS increases when molar ratio of MS: n-BA was increased from 1:3 to 2:1 over HC coated with MZ and PSZ catalysts. The selectivity of n-BS was found to be $100 \%$ over MZ. In case of PSZ (HC
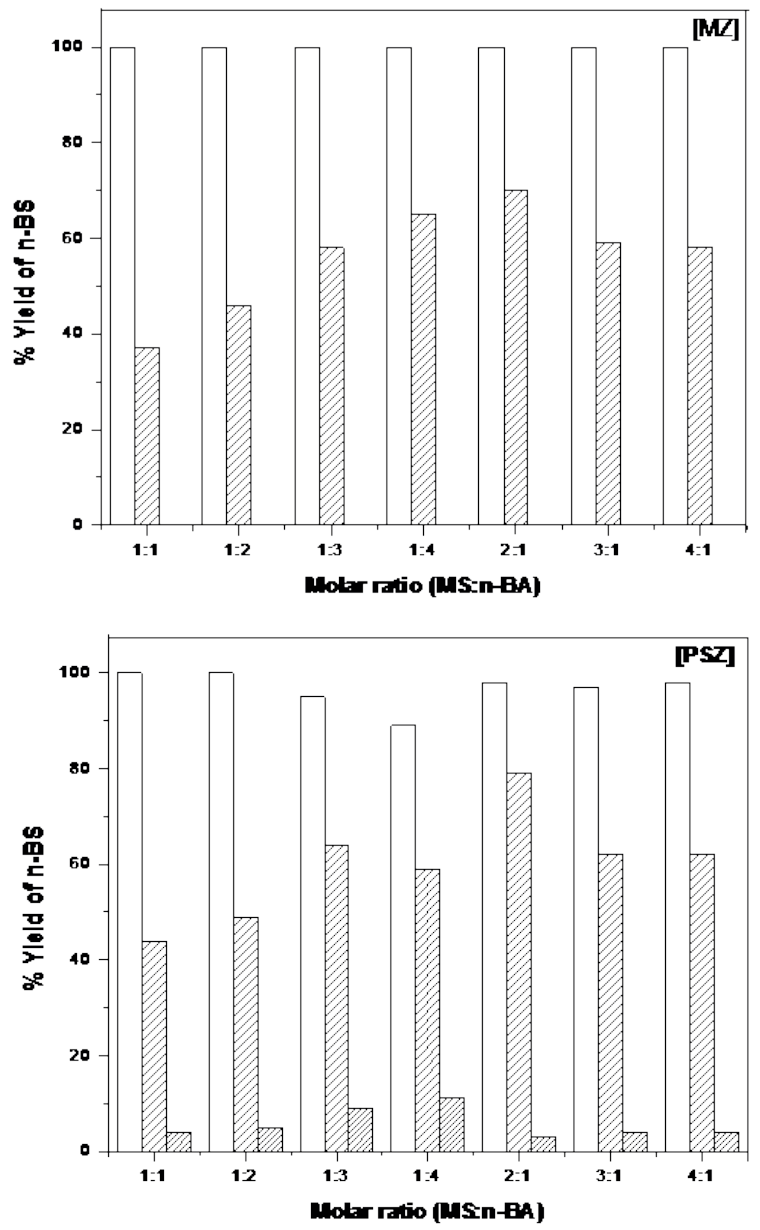

Fig. 9. Influence of molar ratio [Reaction conditions reaction temperature $=403 \mathrm{~K}$, weight of the catalysts $\mathrm{HC}$ coated $=0.4 \mathrm{~g}$, Molar ratio $=2: 1$, reaction time $4 \mathrm{~h}$. Selectivity of $n-B S$, Conversion of n-BA， Selectivity of DBE] 

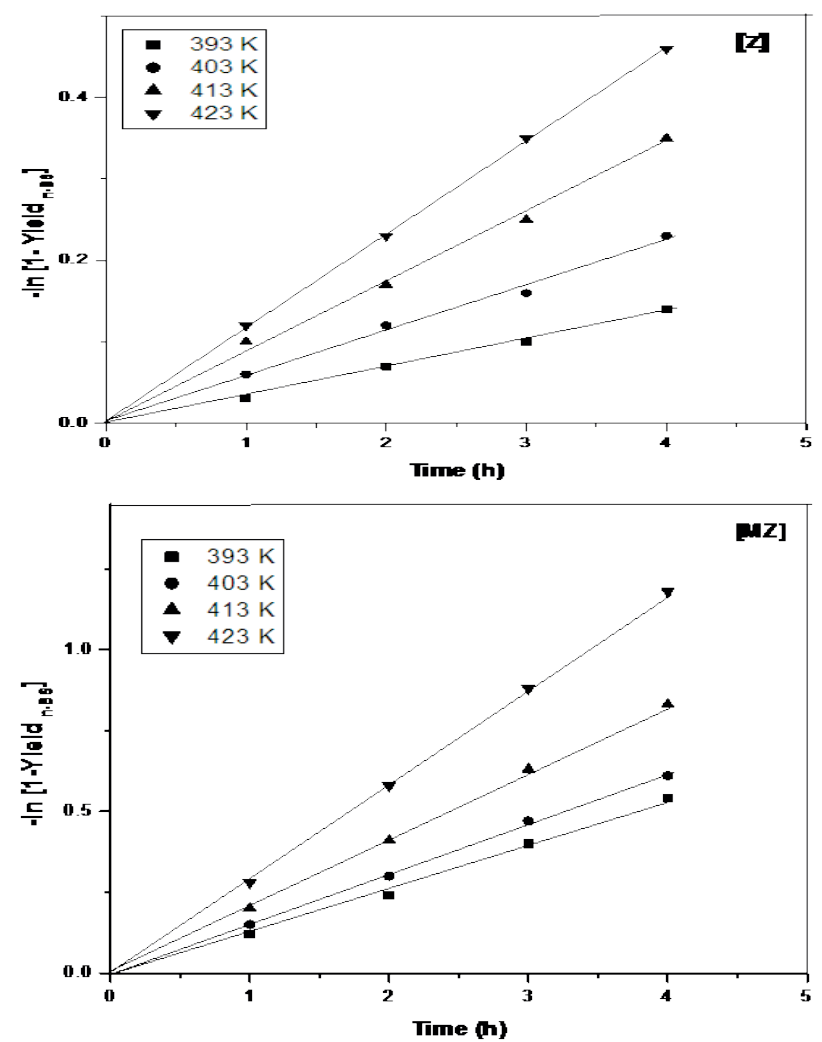
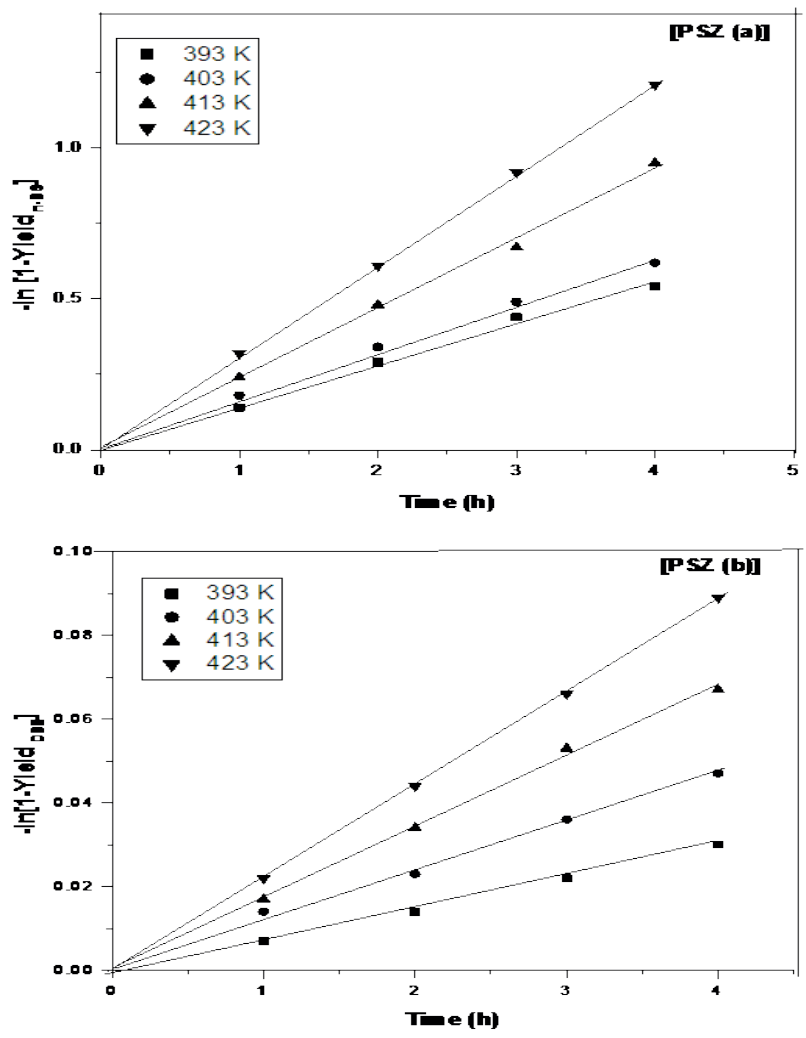

Fig. 10. Plot of first order equation for the formation of n-butyl salicylate and di-butyl ether over Z, MZ and PSZ at 383 $\mathrm{K}, 393 \mathrm{~K}, 403 \mathrm{~K}$ and $413 \mathrm{~K}$

coated), when the concentration of n-BA increased, the selectivity of n-butyl salicylate was found to decrease due to the formation of di-butyl ether. But the effect was only to an extent of 5 to $12 \%$ as shown in Fig. 9. In the present case, the molar ratio of methyl salicylate to n- butyl alcohol 2:1 was found to be the best adequate performance.

\section{Kinetic studies}

In order to influence of kinetics studies, The effect of activation energy, temperature coefficient and mass transfer limitations were calculated from the molar ratio of 1:1 to 4:1 (n-BA: MS) were synthesis of n- butyl salicylate reaction were carried out over $\mathrm{HC}$ coated Z, MZ and PSZ catalysts.

The effect of mass transfer limitations by varying the amount of catalysts with increase the conversion of n-BA over amount of the catalysts has been observed. The plots are nearly linear in all the cases, indicating the transesterification (and etherification in case of HC coated PSZ only) to be a first-order reaction. In case of detail study, the lack of mass transport limitation, rate of the reaction would be relative to the weight of the HC coated catalytic materials (Madon et al., 1982; Mallik et al., 2006; Thimmaraju et al., 2015). In figure
9, plots of $-\ln$ (1-yield n-BS) vs reaction time at different temperature ranging from 393-423 K carried out over HC coated catalytic materials (Z, MZ and PSZ). Since di-butyl ether was also formed over HC coated PSZ, the transesterification and etherification were treated separately to get the kinetic data (Fig. 10). The energy of activation (Ea) and temperature coefficients are calculated from the Arrhenius equation and the eqn 1 and 2 are given in Table III. The values of energy of activation for transesterification reaction was follow the order;

$\mathrm{Z}>\mathrm{MZ}>\mathrm{PSZ}$.

HC coated with zirconia has the highest energy of activation among the catalysts used in the study. As for as HC coated with PSZ $(14.92 \mathrm{KJ} / \mathrm{mol})$ and $\mathrm{MZ}(16.81 \mathrm{KJ} / \mathrm{mol})$ catalysts are concerned, the Ea is almost similar, which means that the reaction proceeds under the same kinetic mechanism. This indicates that the transesterification is equally facile over $\mathrm{HC}$ coated PSZ and MZ. The energy of activation for the formation of di-butyl ether over HC coated with PSZ catalyst was found to be $60.5 \mathrm{KJ} / \mathrm{mol}$. Consequently, HC coated with MZ could be a preferred catalyst for n-butyl salicylate 
Table III. Reaction rate constant, energy of activation and temperature coefficients of HC coated Z, MZ, and PSZ catalysts for transesterification of MS with n-BA

\begin{tabular}{|c|c|c|c|c|c|c|c|c|}
\hline \multirow{3}{*}{ Catalyst } & \multirow{2}{*}{\multicolumn{2}{|c|}{ Rate constant (n }} & \multirow{2}{*}{\multicolumn{2}{|c|}{ Rate constant (ether) }} & \multicolumn{2}{|c|}{ Energy of activation [Ea] } & \multicolumn{2}{|c|}{ Temperature } \\
\hline & & & & & \multicolumn{2}{|c|}{ and DBE } & \multicolumn{2}{|c|}{$\begin{array}{l}\text { Coefficient } \\
\qquad\left(\mathrm{K}_{2} / \mathrm{K}_{1}\right)\end{array}$} \\
\hline & $393 \mathrm{~K}\left(\mathrm{~K}_{1}\right)$ & $403 \mathrm{~K}(\mathrm{~K} 2)$ & $393 \mathrm{~K}\left(\mathrm{~K}_{1}\right)$ & $403 \mathrm{~K}(\mathrm{~K} 2)$ & $n-B S$ & DBE & n-BS & DBE \\
\hline $\mathrm{Z}(\mathrm{HC})$ & 0.7 & 1.1 & - & - & 59.52 & - & 1.57 & - \\
\hline $\mathrm{MZ}(\mathrm{HC})$ & 2.2 & 2.5 & - & - & 16.81 & - & 1.36 & - \\
\hline PSZ(HC) & 2.5 & 2.8 & 1.2 & 1.9 & 14.92 & 60.51 & 1.12 & 1.58 \\
\hline
\end{tabular}

[Reaction conditions for Column 3: Reaction time 4 h; reaction temperature 130 0C; amount of HC coated catalyst 0.4 g; molar ratio of MS: n-BA 2:1]

synthesis due to 'moderate and strong' acid sites which are present in MZ catalyst used for the present work (Mohamed and Nagaraju, 2007).

$\mathrm{Ea}=2.303 \mathrm{R} \log \mathrm{K} 2 / \mathrm{K} 1(\mathrm{~T} 1$ x T2 / T2 -T1)

Temperature coefficient $=(\mathrm{K} 2 / \mathrm{K} 1)$

\section{Effect of reactant pre-adsorption}

Consequently, the influence of reactant pre-adsorption has been studied under with the MS: n-BA (2:1), HC coated MZ $(0.4 \mathrm{~g})$. It has been premixed with the methyl salicylate, n-butyl alcohol and both methyl salicylate and n-butyl alcohol for $24 \mathrm{~h}$ at room temperature and then reaction

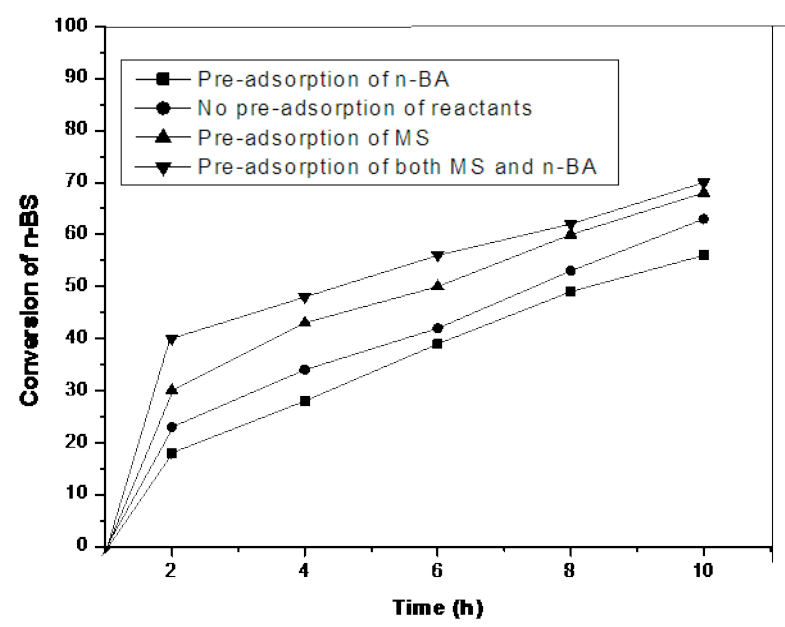

Fig. 11. Influence of Pre-adsorption studies of reactants on HC coated catalysts on transesterification of MS with n-BA [Reaction conditions: reaction temperature $=1300 \mathrm{C}$, weight of the catalysts $\mathrm{HC}$ coated = $0.4 \mathrm{~g}$, Molar ratio $=2: 1$, reaction time $4 \mathrm{~h}$ temperature has been raised up to $130^{\circ} \mathrm{C}$ after adding remaining reactants. (Mitran $\mathrm{G}$ et. al., 2015). The plots are shown yield (\%) of n-butyl salicylates vs reaction time as shown in the figure 10. It shows that the highest yield of n-butyl salicylate obtained when premixing with the $\mathrm{HC}$ coated MZ catalysts. Fig. 10 indicates that the premixing of both the reactants (MS and n-BA) shows maximum and minimum yield was obtained by premixing with n-butyl alcohol. As the reaction rate was higher when premixing the catalyst with both methyl salicylate and n-butyl alcohol compared with the reaction with no premixing, this suggests that the reaction needs the chemisorption of both methyl salicylate and n-butyl alcohol involving a Langmuir Hinshelwood type mechanism (Teo et al., 2004).

The results in Fig. 10, also suggested a strong adsorption of n-butyl alcohol and a weak adsorption of methyl salicylate competing for the same adsorption sites. This shows that the linear line in the Fig. 11 results proposing a stronger chemisorption of the alcohol than the ester. The resultant plot without premixing of $\mathrm{MS}$ and n-BA is also obtainable for similarity. n-butyl alcohol with moderate yield was obtained under non-premixing condition of reactant with the $\mathrm{HC}$ coated $\mathrm{MZ}$ catalyst. The obtained (Fig. 11) conversion of n-butyl salicylate vs reaction time has been concerning to Langmuir Hinshelwood method.

Transesterification of n-butyl salicylate follows L-H mechanism, It is possible by aliphatic alcohol and an aromatic ester (Scheme 2) of methyl group are adsorbed on the acidic sites of the modified zirconia, protonation of the carbonyl group by acidic catalysts to the formation of carbocation. Then after that a nucleophilic attack of the alcohol produces a tetrahedral carbocation intermediate. Finally it eliminates 
methanol and the formation of new ester (n-butyl salicylate) and to regenerate of the acidic catalysts $\mathrm{H}+$.

Effect of reusability of honeycomb form of catalysts as well as powder form of catalysts

The used catalysts ( $\mathrm{Z}, \mathrm{MZ}$ and PSZ) recovered from the liquid sample was washed with acetone, dried at $393 \mathrm{~K}$ for $2 \mathrm{~h}$ and calcined to remove organic impurities at $823 \mathrm{~K}$ for $1 \mathrm{~h}$. The test reaction carrying out the repeated runs of the fresh reaction mixture with the same honeycomb coated catalyst for the synthesis of n-butyl salicylate (Shyamsundar et al., 2015). After every reaction cycle the used catalysts were reactivated by using the procedure as described above. The recycled catalysts show good conversion towards the formation of trans-ester. It could be seen that the HC coated catalysts have more reusability compared to their powder forms. It was observed that small amount of coated catalysts has been decreased. The result related to the reusability studies are given in Table IV.

\section{Conclusion}

From a series of examination, Honeycomb coated zirconia and its modified forms such as Z, MZ and PSZ are effective acid catalysts in the transesterification of n-butyl salicylate. $\mathrm{Mo}(\mathrm{VI}) / \mathrm{ZrO}_{2}$ can be used as excellent among the catalytic materials for the transesterification of MS with n-BA. A good correlation between the yield of the transester and the acidity of the catalytic material was observed. $\mathrm{Mo}(\mathrm{VI}) / \mathrm{ZrO}_{2}$ were found to be $100 \%$ selective and $\sim 70 \%$ of the formation of

Table IV. Reusability of solid acid catalysts (both HC coated and powder forms)

\begin{tabular}{cccccccc}
\hline $\begin{array}{c}\text { Sl } \\
\text { No catalysts }\end{array}$ & \multicolumn{6}{c}{ No of reaction cycles } \\
\hline & & 1 & 2 & 3 & 4 & 5 & 6 \\
\hline 1 & Z & $38(20)$ & $38(19)$ & $36(19)$ & $35(17)$ & $33(15)$ & $32(14)$ \\
\hline 2 & PSZ & $80(38)$ & $79(36)$ & $69(34)$ & $64(32)$ & $63(30)$ & $63(29)$ \\
\hline 3 & MZ & $70(32)$ & $68(32)$ & $67(30)$ & $65(28)$ & $60(26)$ & $60(25)$ \\
\hline
\end{tabular}

[Reaction conditions for Column 3: Reaction time $4 \mathrm{~h}$; reaction temperature $403 \mathrm{~K}$; weight of $\mathrm{HC}$ coated catalyst $0.4 \mathrm{~g}$; molar ratio of MS: n-BA 2:1]

n-butyl salicylate under suitable reaction conditions. But in case of PSZ was found to be $80 \%$ product and $10 \%$ as by-product (di-butyl ether) was found to be related to the strength of the catalysts. A good correlation between the total surface acidity, PXRD and catalytic activity was observed over zirconia and its modified forms. Kinetic study also reveals Molybdenum $\left(\mathrm{Mo}(\mathrm{VI}) / \mathrm{ZrO}_{2}\right)$ could be a facile catalyst as it exhibits the lowest Ea (16.81 kJmol-1), is easily reactivable, and is reusable without formation of byproduct (DBE). The reactant pre-adsorption experiments of n-butyl salicylate follow Langmuir-Hinshelwood mechanism. HC coated catalysts are inexpensive and more reusable catalysts up to 6 reaction cycles without deactivation and no loss in catalytic activity and can be replace traditionally by homogeneous acid catalysts. As a result HC coated catalysts are more valuable than their powder forms.

\section{Acknowledgements}

Authors are grateful for the financial support given by VGST, Government of Karnataka (GRD-375/2014-15). Authors also thank the authorities of St. Joseph College, Bangalore, For PXRD and FTIR analysis. The authors are also thankful to IITM, Chennai for TPD analysis, IISC Bangalore for providing SEM and TEM images.

\section{References}

Ahmedzeki NS, Al-Hassani M and Aljendeel H (2010), Kinetic study of esterification reaction, Al-Khwarizmi. Eng. J 25: 33-42.

Arai H and Machida M (2009), Recent progress in high-temperature catalytic combustion, Catal. Today, 10: $81-94$.

Banzquart A, Vanhove C, Pouilloux Y and Joel Barrault (2001), Glycerol transesterification with methyl stearate over solid basic catalysts: I. Relationship between activity and basicity, Appl. Catal. A: General 218: $1-11$.

Bhatia S (2008), Frangrance material reviews, Food. Chem. Toxicol 46: 250-285.

Corma A, Ibora, S, Miquel S and Primo P (1998), Catalysts for the production of fine chemicals: production of food emulsifiers, monoglycerides by glycolysis of fats with solid base catalysts, J. Catal 173: $315-321$.

Davydov A (2003), Molecular spectroscopy of oxide catalysts surfaces, DOI: 10.1002/0470867981.ch4

D' Souza J and Nagaraju N (2004), Vapor phase transesterification over solid acids for the synthesis of isoamyl salicylate, Ind. J. Chem. Technol 11: 401- 409 .

Furlan RLE, Mata EG and Mascaretti OA (1998), Butyl stannonic acid catalyzed transesterification of carboxylic esters, Tetrahedron. Lett. 4: 2257-2260. 
Ghesti, GF, Lemos de Macedo J, Parente VCI, Dias JS, Silvia CL, Dias (2009), Synthesis, characterization and reactivity of Lewis acid/surfactant cerium trisdodecylsulfate catalyst for transesterification and esterification reactions, Appl Catalysis A: General 355: 139-147.

Heck RM, Gulati, S and Rarranto SJ (2001), The application of monoliths for gas phase catalytic reactions, $J$. Chem. Eng. 82: 149-156.

Illankumaran P and Verkade JG (1999), P(RNCH2CH2)3N: Efficient catalysts for transesterifications, acylations, and deacylations, J. Org. Chem. 64: 3086-3090.

Kim WB and Lee JS (1999), Gas Phase Transesterification of Dimethyl carbonate and Phenol over Supported Titanium Dioxide, J. Catal. 185: 307-313.

Klinghoffer AA, Cerro RL and Abraham MA (1998), Catalytic wet oxidation of acetic acid using platinum on alumina monolith catalyst, Catal. Today 40: 59-71.

Knickerbocker SH, Kumar AH and Herson LW (1993), Cordierite glass ceramics for multilayer ceramic packaging, Am. Ceram. Soc. Bull. 72: 90-95.

Lachmann IM (1986), Monolith honeycomb supports for catalysis, Sprechsaal 119: 1116-1119.

Lachmann IM and Williams JL (1992), Extruded monolithic catalyst supports, Catal. Today 14: 317-329.

Lapczynski A, Jones, L and Mc Ginty LD (2007), Fragrance Material Review on Butyl Salicylate, Food. Chem. Toxicol. 45: 381-386.

Liu Bo, Jun Du, Xiawei Lv, Yue Qiu and Changyuan Tao (2015), Wash coating of cordierite honeycomb with vanadia-tungsta-titania mixed oxides for selective catalytic reduction of $\mathrm{NO}$ with $\mathrm{NH}_{3}$, Catal. Sci. Technol. 5: 1241-1250.

Madon RJ and Boudar, M (1982), Experimental Criterion for the Absence of Artifacts in the Measurement of Rates of Heterogeneous Catalytic Reactions, Ind. Eng. Chem. Fundam. 21: 438 - 447.

Mallik S, Dash S, Parida KM and Mohapatra BK (2006), Synthesis, characterization, and catalytic activity of phosphomolybdic acid supported on hydrous zirconia, J. Colloid. Inter. Sci. 300: 237-243.

Martin Alonso D, Lopez Granados M, Mariscal R and Douhal A (2009), Polarity of the acid chain of esters and transesterification activity of acid catalysts, $J$. Catal. 262: 18-26.
Mitran G, Yuzhakova T, Popescu I and Marcu, IC (2015), Study of the esterification reaction of acetic acid with n-butanol over supported WO3 catalysts, J. Mol. Catl. A. 396: 275-281.

Mohamed Shamshuddin SZ and Nagaraju. N (2007), Liquid phase transesterification of methyl salicylate and phenol over solid acids: Kinetic studies J. Mol. Catal. A 273: 55-63.

Mohamed Shamshuddin SZ and Nagaraju N (2006), Transesterification: Salol synthesis over solid acids, Catal. Commun. 7: 593-599.

Mohamed Shamshuddin SZ, Shyamsundar M, Thimmaraju N, Venkatesh and Vathsalya (2012), Synthesis, characterization and catalytic activity studies on cordierite honeycomb coated with $\mathrm{ZrO} 2$ based solid super acids, C. R. Chemie. 15: 799-807.

Monica CG, Diana CSA, Azevedo CL, Cavalcante, Jose Santamaria - Gonzalez J, Merida Robles M, Tost RM, Castellon ER, Lopez AJ and Torres V ( 2009), Transesterification of ethyl butyrate with methanol using $\mathrm{MgO} / \mathrm{CaO}$ catalysts, J. Mol. Catal 300: 19-24.

Nijhuis TA, Beers, AEW, Vergunst T, Hoek T, Kapteijn F and Moulijn TA (2001), Monolithic catalysts as more efficient three-phase reactors, Catal. Rev. Sci. Eng. 43: 345-380.

Okada R, Kameshima Y, Madhusoodana CD and Das RN (2004), Preparation of zeolite coated cordierite honeycombs prepared by an in situ crystallization method, Science. Technol. Adv. Matt. 5: 479-484.

Otera J, Dan-oh N and Nozaki H (1991), Novel template effects of distannoxane catalysts in highly efficient transesterification and esterification, J. Org. Chem. 173: 5307-5311.

Otera T (1993), Transesterification, Chem. Rev 93: 1449-1470.

Patil KC, Hegde MS, Tanu Rattan and Aruna ST (2008), Chemistry of nano crystalline oxide materials, combustion synthesis properties and applications, World Science publishing Pvt. Ltd., Singapore.

Qureshi ZS, Deshmukh KM, Bhor MD and Bhanage BM (2009), Bronsted acidic ionic liquid as an efficient and reusable catalyst for transesterification of $\beta$-ketoesters, Catal Commun 10: 833-837.

Reddy BM and Patil MK (2009), Organic syntheses and transformations catalyzed by sulphated zirconia, Chem. Rev. Chem. Rev. 109: 2185-2208. 
Reddy BM, Patil, M. K and Reddy BT (2008), An Efficient and Ecofriendly WOx- $\mathrm{ZrO}_{2}$ Solid Acid Catalyst for Classical Mannich Reaction, Catal. Let 125: 97-103

Saravanamurugan S, Sujandi, Dae-Soo Han, Jeon-Boon Koo and Sang-Eon Park (2008), Transesterification reactions over morphology controlled amino-functionalized SBA-15 catalysts, Catal. Commun 9: 158-163.

Sharma M, Toor A. P and Wanchoo RK, (2014) Kinetics of the esterification reaction between pentanoic acid and methanol catalyzed by noncorrosive cation exchange resin, Chem. Biochem. Eng. Q 28: 79-85.

Shyamsundar M, Mohamed Shamshuddin SZ and Aniz CU (2015), Cordierite honeycomb monoliths coated with zirconia and its modified forms for biodiesel synthesis from Pongamia glabra, J. Ame. Oil. Chem. Soc 92: 335-344.

Shyamsundar M, Mohamed Shamshuddin SZ and Sahu JN (2013), Catalytic synthesis of biodiesel from pongamia glabra over zirconia, and its modified forms, K. J. Chem. Engg. 30: 2186-2190.

Shyamsundar, M., Mohamed Shamshuddin SZ and Pratap SR (2013), Catalytic synthesis of salicylate esters over cordierite honeycomb coated with $\mathrm{Mo}(\mathrm{VI}) / \mathrm{ZrO}_{2}$, Modern. Research. Catal 2: 39-41

Srinivas D, Srivastava R and Ratnasamy P (2004), Transesterifications over titanosilicate molecular sieves, Catal. Today 96: 127-133.

Staton MG, Allen CB, Kissling RM, Lincoln AL and Gagne MR (1998), New catalysts for the ester-interchange reaction: the role of alkali-metal alkoxide clusters in achieving unprecedented reaction rates, J. Am. Chem. Soc. 120: 5981-5989.

Subramanian MA, Corbin DA and Chowdhary U (1993), Better ceramic substrates through Zeolites, Bull. Mater. Sci. 26: 665-678.

Sharma S (2009), PhD Thesis, Gas phase and electro catalytic reaction over $\mathrm{Pt}, \mathrm{Pd}$ ions substituted $\mathrm{CeO}_{2}$, $\mathrm{TiO}_{2}$ catalysts and electronic interaction between noble metal ions and the reducible oxide.
Teo HTR and Saha B (2004), Heterogeneous catalysed esterification of acetic acid with isoamyl alcohol: kinetic studies, J. Catal. 228: 174-182.

Thevenin PO, Menon PG and Jara SG (2003), Catalytic process to convert methane: partial or total oxidation part II Catalytic total oxidation of methane. Catal. Tech. 7: 10-22.

Thimmaraju N, Mohamed Shamshuddin SZ, Pratap SR and Raja K (2015), Efficient microwave synthesis of novel aromatic esters catalyzed by zirconia and its modified forms: a kinetic study, RSC Advances 5: 99517-99528.

Thimmaraju N, Mohamed Shamshuddin SZ, Pratap SR and Venkatesh (2014), Transesterification of diethyl malonate with benzyl alcohol catalyzed by modified zirconia: Kinetic study, J. Mol. Catal. A. General 391: $55-65$.

Thimmaraju N, Pratap SR and Mohamed Shamshuddin SZ (2012), Honeycomb monolith coated with $\mathrm{Mo}(\mathrm{VI}) / \mathrm{ZrO}_{2}$ as a versatile catalyst system for liquid phase transesterification, J. K. Chem. Soc. 56: 563-570.

Trimm DL (1995), Materials selection and design of high-temperature catalytic combustion units, Catal. Today 26: 231-240.

Vane JR and Botting RM (1992), Aspirin and other salicylates, $1^{\text {st }}$ Ed. Chapman and Hall, London.

Vijaykumar Marakatti S, Ganapathi V Shanbag and Halgeri AB (2013), Sulphated zirconia: an efficient and reusable acid catalyst for the selective synthesis of 4-phenyl-1, 3-dioxane by Prins cyclization of styrene, Appl. Catal. A: General 451, 71-78.

Yip SF, Cheung HY, Zhou Z and Kwong FY (2007), Room-temperature copper-catalyzed alpha-arylation of malonates, Org. Lett 9: 3469-3472.

Yong Tae Kim and Eun duck Park (2009), Deactivation phenomena of $\mathrm{MoO}_{3} / \mathrm{SiO}_{2}$ and $\mathrm{TiO}_{2} / \mathrm{SiO}_{2}$ during Transesterification between dimethyl carbonate and Phenol, Appl Catal. A: General 356: 211-215. 